\title{
Assessment of Total Climate Change Impacts on the Agricultural Sector of Cyprus
}

\author{
Christina Papadaskalopoulou ${ }^{1, *}$, Marco Moriondo ${ }^{2}$ (D) Ioannis Lemesios ${ }^{3}$, Anna Karali ${ }^{3}$, \\ Angeliki Konsta ${ }^{1}$, Camilla Dibari ${ }^{4}$ (D), Lorenzo Brilli ${ }^{2}$, Konstantinos V. Varotsos ${ }^{3}$, \\ Andreas Stylianou ${ }^{5}$ (D), Maria Loizidou ${ }^{1}$, Marinos Markou ${ }^{5}$ and Christos Giannakopoulos $^{3}(\mathbb{D}$ \\ 1 School of Chemical Engineering, National Technical University of Athens, 9 Iroon Polytechniou Str., \\ Zographou Campus, 15773 Athens, Greece; aggelikonsta@gmail.com (A.K.); mloiz@chemeng.ntua.gr (M.L.) \\ 2 Institute of BioEconomy, National Research Council (IBE-CNR), via Madonna del Piano, 10 Firenze, Italy; \\ marco.moriondo@cnr.it (M.M.); lorenzo.brilli@unifi.it (L.B.) \\ 3 Institute for Environmental Research and Sustainable Development, National Observatory of Athens, \\ Lofos Koufou, P. Pendeli, 15236 Athens, Greece; jlemesios@noa.gr (I.L.); akarali@noa.gr (A.K.); \\ varotsos@noa.gr (K.V.V.); cgiannak@noa.gr (C.G.) \\ 4 Department of Agricultural Sciences and Technologies, University of Florenze, DAGRI, Piazzale delle \\ Cascine 18, 50144 Florence, Italy; camilla.dibari@unifi.it \\ 5 Agricultural Research Institute, Ministry of Agriculture, Rural Development and Environment, \\ Athalassa Forest, Nicosia 1516, Cyprus; a.stylianou@ari.gov.cy (A.S.); markou@ari.gov.cy (M.M.) \\ * Correspondence: chpapad@chemeng.ntua.gr
}

Received: 9 May 2020; Accepted: 6 June 2020; Published: 9 June 2020

\begin{abstract}
In this paper, the results of a climate change impact and vulnerability assessment conducted for the agricultural sector of Cyprus are presented. The assessment is based on the outputs of specialized climatic and crop models, while it incorporates quantified socio-economic vulnerability indicators of the Cypriot agriculture. The results are aggregated at municipal level in order to support regional and local adaptation planning. The assessment was performed for two representative concentration pathways (RCP4.5, RCP8.5), as well as for extreme climatic scenarios. Following, an economic assessment was made on the expected change in revenues of the agricultural sector. The results of climatic simulations indicated that future increases in temperature will be characterized by a strong seasonal trend, with the highest increases occurring in summer. Precipitation is expected to decrease throughout the island, where the highest decreases $(50 \%)$ are expected during summer (RCP8.5). This trend will affect mainly tomato, grapevine, and olive tree, whose growing cycle takes place during summer. By contrast, crops covering autumn-winter season, such as potato, barley, and wheat, are expected to partially avoid harsh summer conditions. The results of the economic assessment show that the changes in total revenues are insignificant, because, under all scenarios, a loss in one crop is compensated by a gain in another crop. However, the farmers as well as the government should take action to increase the resilience of the agricultural sector, with a special focus on those crops and areas that are expected to be adversely affected by climate change impacts.
\end{abstract}

Keywords: climate change; impacts; agriculture; crop yield; vulnerability; socio-economic; Cyprus

\section{Introduction}

Climate change affects many economic sectors, with agriculture being one of the most exposed [1], as it directly depends on climatic factors such as temperature, sunlight, and precipitation for its viability. Climate change impacts on agriculture vary across regions, with the adverse impacts for the Mediterranean region mainly referring to reduced crop yields due to the increase in heat extremes, 
the decrease in precipitation, and the increased water demand for irrigation owing to more frequent and prolonged periods of droughts [1].

The 2019 survey of the European Environment Agency (EEA) [1] demonstrates that, of the 28 European (EU) countries that have adopted their national adaptation strategies, twenty EU countries have conducted climate change impact and vulnerability (CCIV) assessments for their agricultural sectors.

The national sector-specific CCIV assessments usually do not employ models for quantifying the climate change impacts on their agricultural production, but they rather present results of existing literature or expert elicitation [2,3]. There are several research projects having published geospatial CCIV assessments for agriculture at European or wider regional level [3]; however, these are not very useful for adaptation planning and allocation of resources at regional or local level within a country, as the level of analysis is inadequate. In a few national CCIV assessments (Spanish, Finnish, German, Czech, Swiss, Norwegian), agronomic indicators (e.g., length of vegetation period, crop yield) are estimated at spatial level with the use of models. Furthermore, in a few CCIV assessments, composite indicators encompassing a number of relevant impact and vulnerability indicators are also employed [2], which, however, are usually estimated at national level and not at local level.

The national adaptation strategy of Cyprus [4] is based on the results of CCIVs conducted for eleven policy areas, including agriculture [5]. However, as the CCIV for agriculture does not focus on the local and crop-specific climate change impacts, the adaptation measures foreseen in the relevant national plan are more generic and call for further analysis in order to achieve a more targeted adaptation policy.

In this paper, the results of a new, more detailed CCIV conducted for the agricultural sector of Cyprus are presented. The assessment took place in the framework of the LIFE ADAPT2CLIMA project, among the goals of which was to develop adaptation strategies for the agricultural sectors of three of the largest islands of the Mediterranean region. The assessment is made with the employment of specialized climatic and crop models, while it incorporates quantified socio-economic vulnerability indicators, specific to the particular characteristics of the Cypriot agriculture. The results are aggregated at municipal level, in order to support well-informed and robust adaptation planning at regional and local level. In fact, this CCIV will inform the annual revision of the National Adaptation Plan of Cyprus, as well as the new Rural Development Programme for the period 2021-2027.

The CCIV is conducted for the area of the island of Cyprus, which is under the effective control of the Government of the Republic of Cyprus. The island of Cyprus lies in the northeastern most corner of the Mediterranean basin and is characterized by a warm temperate climate with hot and dry summers, typical for the Mediterranean region, while part of the island is classified as hot and arid [6]. The percentage of cultivated area over the study area is approximately $13 \%$ [7].

Overall, six crops were taken into account in the impact assessment, that is, barley, wheat, tomatoes, potatoes, olive trees, and grapevines. These crops are considered to be important for the agricultural sector of Cyprus, as they contributed approximately $60 \%$ to the total revenues of the sector, during the period 2010-2015, while the area cultivated with these crops constituted $50 \%$ of the total cultivated area in Cyprus in 2015 [7]. On average, during the period 2010-2015, potatoes recorded the highest total value of production, with a $25 \%$ share in the total value of crop production, followed by olives with an $11 \%$ share, barley and wheat with $9 \%$, tomatoes with $7 \%$, and grapes with $6 \%$ [7]. In Cyprus, cultivated areas with grapevines and olive trees are characterized as areas of high natural value (HNV) and as protected landscapes [8]. HNV areas are cultivated with traditional methods, have high ecological value, and support great biodiversity. Protected landscapes are areas of high aesthetical, ecological, and cultural importance [8]. The grapevines cultivated in Cyprus are traditional varieties that are adjusted to the local climatic and other conditions [8]. Cereals are widely cultivated in Cyprus, as almost $25 \%$ of the total utilised agricultural area is covered with barley and wheat. Of the examined crops, potatoes and grapevine products are among the crop products of the primary sector with high added value [8], while potato is also the most important raw agricultural export product of Cyprus [9]. 
Crop growth performances were evaluated using a set of crop simulation models calibrated for the most important cultivations over the island. In particular, the CropSyst model [10] was used for wheat, barley, tomato, and potato; the OliveModel.CNR [11] was used for olive; and the UNIFI.GrapeML [12] was used for grapevine. CropSyst is a multi-year, multi-crop simulation model that simulates the soil water and nitrogen budgets, crop growth and development, and crop yield. The OliveModel.CNR is a process-based model that simulates growth and development of an olive agroecosystem, including the olive tree and grass cover growth and their competition for water. Finally, the UNIFI.GrapeML is a grapevine model software used for estimating grapevine growth, yield, and quality in different environments, considering the impact of soil water availability on yield.

\section{Methods}

In this section, the methodology applied for conducting the overall impact assessment for the agricultural sector of Cyprus, as well as the individual components of this assessment, that is, the assessment of climatic hazard, of the intermediate impacts, and of the vulnerability, are presented.

\subsection{Overall Impact Assessment}

The methodology for the assessment of total climate change impacts on agriculture was based on the relevant conceptual framework presented within the latest Assessment Report of the Intergovernmental Panel on Climate change (IPCC) [13]. According to the latter, the total impacts are a result of the interaction of climate change (hazard) and the vulnerability of the exposed system and population. The generic framework was further specialized for the case of agriculture based on the guidance provided by GIZ \& EURAC [14] for the application of the IPCC concept in impact assessments.

In particular, according to [14], the hazard includes the changes in several climatic indicators, which in their turn cause changes in crop yield (intermediate impacts). Vulnerability refers to the sensitivity and adaptive capacity of the exposed agricultural population and cultivated areas, and incorporates both social and economic aspects. However, these are theoretical concepts and do not provide an integrated metric for the quantification of impacts [15].

To provide an overall picture of the total impacts that will encompass all of the aforementioned terms, a combination of the relevant indicators is applied, based on the composite indicator approach [16]. In particular, the individual indicators are aggregated to form composite indicators (CIs) of the main terms, as shown next.

$$
\mathrm{CI}_{\text {total impact }}=\mathrm{f}\left(\mathrm{CI}_{\text {intermediate impact }} ; \mathrm{CI}_{\text {vulnerability }}\right)
$$

where

$$
\begin{gathered}
\mathrm{CI}_{\text {intermediate impact }}=\mathrm{f}\left(\mathrm{I}_{\text {crop yield change }} ; \mathrm{I}_{\text {cultivated area }}\right) \\
\mathrm{CI}_{\text {vulnerability }}=\mathrm{f}\left(\mathrm{CI}_{\text {social vulnerability }} ; \mathrm{CI}_{\text {economic vulnerability }}\right)
\end{gathered}
$$

Individual indicators were normalized by applying the min-max method [16], while a five-class system was applied representing values from "high" to "low" (Table 1). Indicators were assigned with weights that were defined through expert judgement. In particular, a steering committee was set from the beginning of the project bringing together the relevant ADAPT2CLIMA stakeholder groups, that is, representatives from agricultural cooperatives, competent government departments, non-governmental organizations, as well as agronomists and academic staff from relevant fields. Among the goals of the steering committee were to inform the project team with respect to the different stakeholders' views and expectations and to provide advice throughout the project implementation, in order to promote the validation of the project results and, subsequently, their exploitation and uptake [17]. The process of assigning weights to individual indicators was realized through short focus group discussions (FGDs) that took place during workshops, with members of the steering committee 
and the project team. The committee members were asked to provide their opinion on the relevant importance of the different indicators in the form of weights.

Table 1. Classification of normalized values.

\begin{tabular}{cc}
\hline Numerical Scale & Nominal Scale \\
\hline $0-1$ & Low \\
$1-2$ & Low to Medium \\
$2-3$ & Medium \\
$3-4$ & Medium to High \\
$4-5$ & High \\
\hline
\end{tabular}

The indicators are also aggregated at municipal level in order for the total impact results to be expressed at a spatial level suitable for policy making. In Table 2, the classification of crop yield change values and of the cultivated areas per crop at municipal level for the case of Cyprus is presented. It is noted that, in the case of crop yield change, any increase was classified as 0 , as only negative impacts were taken into account.

Table 2. Classification of values on crop yield change and cultivated area at municipal level, Cyprus.

\begin{tabular}{ccccc}
\hline Class & $\begin{array}{c}\text { Reduction in Crop } \\
\text { Yield (\%) }\end{array}$ & $\begin{array}{c}\text { Potatoes, } \\
\text { Tomatoes }\end{array}$ & Barley, Wheat & $\begin{array}{c}\text { Vineyard, Olive } \\
\text { Trees }\end{array}$ \\
\cline { 3 - 5 } Low & $0-10$ & $<2$ & $<20$ & $<5$ \\
Low to Medium & $10-20$ & $2-10$ & $20-100$ & $5-10$ \\
Medium & $20-30$ & $10-20$ & $100-200$ & $10-20$ \\
Medium to High & $30-50$ & $20-100$ & $200-600$ & $20-100$ \\
High & $>50$ & $>100$ & $>600$ & $>100$ \\
\hline
\end{tabular}

\subsection{Assessment of Hazards}

The daily maximum and minimum temperature, precipitation, and solar radiation output from the RCA4 regional climate model (RCM) of the Swedish Meteorological and Hydrological Institute [18] were used in the current study. The RCA4 is driven by the HadGEM2-ES [19,20] global climate model (GCM) of the Met Office Hadley Centre (MOHC). This GCM/RCM pair was developed within the EURO-CORDEX initiative. It should be noted that, for the selection of the model, an extensive evaluation analysis of four GCM/RCM pairs against the gridded observational dataset of E-OBS(v17) for the period 1971-2000 was performed, and MOHC-RCA4 was found to better capture the observed seasonal patterns of temperature and precipitation of the study area [21]. In particular, for the comparison of winter and summer climatologies between the E-OBS and the RCMs, Taylor plots [22] for daily maximum and minimum temperatures were used. The analysis revealed that the lowest values, for both overestimation and underestimation of the variability for both seasons, were calculated for the RCA4 model driven by the MOHC HadGEM2-ES global climate model. In addition, the model exhibited the lowest root mean square error (RMSE). Moreover, for precipitation, the analysis of the mean spatial biases over the island on annual and seasonal basis revealed that the selected model exhibited the lowest relative biases compared with E-OBS.

The climatic data cover the period from 1971 to 2098 at a horizontal resolution of $0.11^{\circ}(\sim 12 \mathrm{~km})$. Present day simulations cover the period 1971-2000, which is used as reference for comparison with future projections for the period 2031-2060. The impact assessment was performed for the mean climatic conditions expected for the 2031-2060 period, based on two representative concentration pathways, RCP4.5 and RCP8.5 [23,24], as well as for extreme climatic scenarios for the same period based on the RCP8.5 scenario. These include the intense cold/warm year, that is, future climatic conditions for the year with the lowest/highest mean annual minimum/maximum temperature (hence 
called RCP8.5 cold and RCP8.5 warm, respectively) and the intense dry/wet year, that is, future climatic conditions for the year with the lowest/highest annual total precipitation amount (hence called RCP8.5 dry and RCP8.5 wet, respectively).

The analysis of the model results for the present and future is based on the average of the 30-year periods selected. This applies to the overall impact assessment performed for the mean conditions over the future 30-year period. Regarding the climatic conditions of the future extreme year, a single year presenting the extreme characteristic in the future 30-year period was selected.

\subsection{Assessment of Intermediate Impact}

A set of crop simulation models, fed with the outputs of the MOHC model, was calibrated for the examined crops over the island of Cyprus. Specifically, crop growth simulations were carried out using the model CropSyst [10] for wheat, barley, tomato, and potato; the Olive.CNR [11] for olive tree; and the UNIFI.GrapeML [12] for grapevine.

Even though these crop growth models present different detail level at which the specific growth processes are described, all of them share the same architecture. In particular, each growth model simulates the main phenological stages of crops: emergence, anthesis, grain filling, and maturation for sowing crop and bud break anthesis and maturation for olive tree and grapevine. Potential biomass accumulation is dependent on radiation and water use efficiency (RUE, WUE) and plant transpiration, and may be reduced in the case of water shortage or nitrogen stress. Final yield is calculated considering a fixed ratio between final yield and total biomass (harvest index), which may be reduced according to the approach reported in Moriondo et al. [11,25], by considering the possible effect of heat or water stress at anthesis. Each model requires meteorological data on a daily time step and soil available water content. The effect of higher $\mathrm{CO}_{2}$ concentration in future scenarios is accounted for by increasing both WUE and RUE according to the literature.

CropSyst was calibrated by adjusting the cultivar parameters relevant to phenology and biomass accumulation (RUE and WUE). The calibration process included barley and wheat, while for potato and tomato, the crop parameters already calibrated for specific varieties were selected. All crops were simulated in rain fed conditions. In the Cropsyst model, which includes the simulation of nitrogen balance, fertilization was set to dates specific for each crop. For durum wheat and barley, nitrogen fertilization was split at sowing $(50 \mathrm{~kg})$, shooting $(70 \mathrm{~kg})$, and anthesis $(30 \mathrm{~kg})$. For tomato, $30 \mathrm{~kg}$ was provided at planting, $50 \mathrm{~kg}$ at fruit set, and $80 \mathrm{~kg}$ at ripening. For potato, $80 \mathrm{~kg}$ at planting, $30 \mathrm{~kg}$ at flowering, and $40 \mathrm{~kg}$ at tuber filling. The harvest date was set 15 days after maturity stage (see Table 3). The models Olive.CNR and Unifi.GrapeML do not simulate the soil nitrogen balance and, therefore, nitrogen is not considered a limiting factor in the simulation.

Table 3. Sowing dates tested for barley, wheat, potato, and tomato and precocity levels for grapevine and olive tree.

\begin{tabular}{|c|c|c|c|c|c|c|c|}
\hline \multicolumn{2}{|c|}{ Barley } & \multicolumn{2}{|c|}{ Wheat } & \multicolumn{2}{|c|}{ Potato } & \multicolumn{2}{|c|}{ Tomato } \\
\hline Early autumn & 10 November & Early autumn & 10 November & - & - & Early winter & 30 January \\
\hline Late autumn & 30 November & Late autumn & 30 November & Late autumn & 20 October & Late winter & 28 February \\
\hline Winter & 31 January & Winter & 31 January & Early winter & 15 November & Early spring & $30 \mathrm{March}$ \\
\hline Spring & 15 February & Spring & 15 February & Late winter & 20 December & Late spring & 30 April \\
\hline \multicolumn{2}{|l|}{-} & \multicolumn{2}{|c|}{ Grapevine } & \multicolumn{4}{|c|}{ Olive tree } \\
\hline \multicolumn{2}{|c|}{$\begin{array}{l}\text { Precocity level (day } \\
\text { of the year) }\end{array}$} & Budbreak & \multicolumn{2}{|c|}{ Harvest } & \multicolumn{2}{|c|}{ Flowering } & Harvest \\
\hline \multicolumn{2}{|c|}{ Early } & 80-90 & \multicolumn{2}{|c|}{$235-240$} & \multicolumn{2}{|c|}{$145-155$} & $240-270$ \\
\hline \multicolumn{2}{|c|}{ Medium } & $100-110$ & \multicolumn{2}{|c|}{$260-270$} & \multicolumn{2}{|c|}{-} & - \\
\hline \multicolumn{2}{|c|}{ Late } & $110-130$ & \multicolumn{2}{|c|}{$265-275$} & \multicolumn{2}{|c|}{$160-170$} & $300-330$ \\
\hline
\end{tabular}

The models were applied for the reference period (1971-2000) considering a $\mathrm{CO}_{2}$ concentration of 360 ppm and for the period 2031-2060, under the future scenarios RCP 4.5 and 8.5 with a reference $\mathrm{CO}_{2}$ concentration of 485 and 540 ppm, respectively. Soil data, texture (\% of clay, silt, and sand) and soil 
depth, were extracted from the Harmonized World Soil Database and rescaled to a spatial resolution of $12 \mathrm{~km}$, from its original resolution of $1 \mathrm{~km}$, to match the spatial resolution of the RCMs. Therefore, the modelling output results on crop yield have the same resolution of $12 \mathrm{~km}$, which was subsequently changed to the respective municipal level analysis, in order to be used in the total impact assessment.

In order to effectively consider the best management practices, in both present and future periods, different sowing times were considered for annual crops and different growing season length for perennial crops. More in detail, for the annual crops (barley, wheat, tomato, and potato), the simulations considered four different sowing times that can be summarized as follows: early, early-medium, medium-late, and late. For grapevine and olive tree, we considered varieties having longer/shorter growing periods, by modifying the original degree day accumulation (DDA) for anthesis and maturity (Table 3). The currently applied crop management practices in Cyprus are presented in Table 4.

Table 4. Applied crop management practices in Cyprus.

\begin{tabular}{ccc}
\hline Crop & \multicolumn{2}{c}{ Management Practices } \\
\hline Barley & & Late winter \\
Wheat & Sowing season & Late winter \\
Tomato & & Early spring \\
Potato & & Late winter \\
Grapevine & Precocity level & Medium \\
Olive tree & & Late \\
\hline
\end{tabular}

For each crop, both annual and perennial, the relevant yield performances were previously evaluated by considering different sowing dates (wheat, barley, tomato, and potato) or growing cycle duration (early and late varieties for grapevine and olive tree) in order to detect which is the best strategy for the present period. As a second step, crop yield was calculated for different sowing times (annual crops) and varieties (grapevine and olive tree) and it was compared to the relevant values for the reference period.

\subsection{Vulnerability Assessment}

The vulnerability indicators consist of both social and economic indicators. The social indicators refer to those characteristics of the agricultural population that are considered to increase its sensitivity or decrease its adaptive capacity to climate change impacts. The economic indicators reflect the vulnerability of the agricultural economy of an area to the climate change impacts on crops, owing to the economic importance of crops for the agricultural economy of the area. In Table 5, the vulnerability indicators used in the impact assessment, as well as their type (exposure, sensitivity, adaptive capacity) and the respective sources used for their quantification, are presented.

The values of the social indicators, although available at municipal level, were aggregated at district level, given that most of the indicators refer to the residence location of farm holders and not to the location of their farms. As the aim of this study is to identify the areas that will be affected by climate change impacts in order to focus adaptation actions on them, it was decided that the use of statistical data at municipal level based on the residence location of farmers would be misleading (e.g., many farmers reside in urban areas while their farms are located in rural areas). Instead, the use of data at district level was considered a better alternative, as there are considerably higher chances that the residence location of the farm holder is in the same district as his/her farm.

The relevant data of the social and economic vulnerability indicators for Cyprus are presented in Tables 6 and 7 respectively. The data used for the social indicators were sourced from the latest censuses, while in the case of the economic indicators, the latest five-year data on crop production and revenues were used. 
Table 5. Vulnerability indicators used in the impact assessment for the agricultural sector.

\begin{tabular}{|c|c|c|c|}
\hline Type of Indicator. & Indicator & $\begin{array}{l}\text { Level of } \\
\text { Analysis }\end{array}$ & Source \\
\hline Exposure & Cultivated areas per crop & Farm level & $\begin{array}{l}\text { Cyprus Agricultural Payments } \\
\text { Organization (CAPO), } 2015\end{array}$ \\
\hline Exposure & $\begin{array}{c}\text { Size of agricultural population } \\
\text { (farm holders, their family members } \\
\text { and other employees working at } \\
\text { the farm) }\end{array}$ & Municipal level & $\begin{array}{l}\text { [26] CYSTAT, 2010. Agricultural } \\
\text { census 2010, Agricultural statistics, } \\
\text { Series I, Report No. 8. Cyprus }\end{array}$ \\
\hline Sensitivity & $\begin{array}{l}\text { Share of agricultural population } \\
\text { with respect to the total population } \\
\text { residing in that area }\end{array}$ & Municipal level & $\begin{array}{l}\text { Statistical Service. Republic of Cyprus. } \\
\text { [27] CYSTAT, 2011. Population census. } \\
\text { Population recorded by gender, age, }\end{array}$ \\
\hline Sensitivity & $\begin{array}{l}\text { Dependence of farmers on the } \\
\text { agricultural income (as exclusive or } \\
\text { major source) }\end{array}$ & Municipal level & $\begin{array}{l}\text { district, municipality/community } \\
\text { (1.10.2011). Cyprus Statistical Service. }\end{array}$ \\
\hline Adaptive capacity & $\begin{array}{l}\text { Share of elderly farmers ( }>65 \text { years) } \\
\text { in the total agricultural population } \\
\text { Dependence of the agricultural }\end{array}$ & Municipal level & \\
\hline Sensitivity & $\begin{array}{l}\text { sector to the revenues from a certain } \\
\text { crop (contribution of crop revenues } \\
\text { to the total revenues) }\end{array}$ & Regional level & $\begin{array}{l}\text { [9,28-31] CYSTAT, 2010-2015. } \\
\text { Agricultural Statistics 2010-2015, } \\
\text { Series IL Reports }\end{array}$ \\
\hline Sensitivity & $\begin{array}{l}\text { Economic importance of a crop in } \\
\text { terms of price }\end{array}$ & Regional level & Statistical Service. Republic of Cyprus. \\
\hline
\end{tabular}

Table 6. Examined characteristics of the agricultural population in Cyprus (district level).

\begin{tabular}{ccccc}
\hline District & $\begin{array}{c}\text { Agricultural } \\
\text { Population (abs.) }\end{array}$ & $\begin{array}{c}\text { Share of Agricultural } \\
\text { Population (\%) }\end{array}$ & $\begin{array}{c}\text { Dependence on } \\
\text { Agriculture (\%) }\end{array}$ & $\begin{array}{c}\text { Share of Elderly } \\
\text { Farmers (\%) }\end{array}$ \\
\hline Nicosia & 29,193 & 31 & 51 & 37 \\
Famagusta & 5407 & 12 & 53 & 27 \\
Larnaca & 13,467 & 20 & 47 & 27 \\
Limassol & 22,969 & 37 & 54 & 41 \\
Paphos & 13,872 & 28 & 47 & 33 \\
\hline
\end{tabular}

Table 7. Total cultivated area, average price, and revenues for the examined crops in Cyprus (2010-2015).

\begin{tabular}{cccc}
\hline Crop & Cultivated Area (ha) & Price $(\mathbf{f} / \mathbf{k g})$ & Revenues $\left(\mathbf{f 0 0 0}_{\mathbf{\prime}} \mathbf{s}\right)$ \\
\hline Tomatoes & 305 & 0.65 & 10,717 \\
Potatoes & 4017 & 0.36 & 36,368 \\
Olives & 9472 & 1.18 & 16,093 \\
Grapes & 6525 & 0.37 & 8386 \\
Barley & 44,704 & 0.21 & 8660 \\
Wheat & 11,386 & 0.24 & 4837 \\
\hline
\end{tabular}

\section{Results and Discussion}

In this section, the results of the hazard, intermediate impact, and vulnerability assessments, as well as of the total impact assessment, are presented and critical issues are identified and discussed. Following, an economic assessment is made on the expected gains and losses, based on the results of the intermediate impacts on crop yield change.

\subsection{Hazard}

A comprehensive analysis of mean and extreme climate change indicators relevant to agriculture was undertaken. According to the results of the analysis, an increase in the seasonal average temperature is expected for all seasons under RCP4.5, which will be up to $2^{\circ} \mathrm{C}$ for winter, $3^{\circ} \mathrm{C}$ for summer, and $2.4{ }^{\circ} \mathrm{C}$ for the transient seasons. Under the RCP8.5 scenario, greater increases are projected throughout the year, that is, up to $2.3^{\circ} \mathrm{C}$ for winter, $3.8^{\circ} \mathrm{C}$ for summer, and $3{ }^{\circ} \mathrm{C}$ for the transient seasons. 
Concerning the average annual total precipitation, under the RCP4.5 scenario, the highest decreases of about $10 \%$ are projected in southern and southeastern regions of the island, while under the RCP8.5 scenario, decreases of about $10 \%$ in western and mountainous regions and $15 \%$ in all other regions are expected.

Regarding the precipitation seasonal changes, small increases in winter precipitation of up to $10 \%$ in the western coastal regions under the RCP8.5 scenario are found, while spring precipitation decreases approximately $20 \%$ throughout the island. During summer, under both scenarios, the entire island shows decreases, with the maximum of $60 \%$ located in the western coastal areas under RCP 4.5 and $50 \%$ in the southern-southeastern coastal regions under RCP8.5.

\subsection{Intermediate Impact}

The results of the climatic hazard assessment for the two RCP scenarios are used in the assessment of crop yield change (intermediate impacts). The interaction between climate, $\mathrm{CO}_{2}$ concentration, and crop growing cycle (Table 3) is a key factor to interpret the impact simulated for the crops under study. While higher temperatures and lower precipitation simulated under RCP8.5 are expected to have an adverse effect on crop growth, the higher $\mathrm{CO}_{2}$ concentration under this scenario mitigates such an impact by increasing photosynthetic and water use efficiency. As a matter of fact, the performances of crops are generally higher under RCP8.5 compared with RCP4.5, as the effect of higher $\mathrm{CO}_{2}$ concentration ( 540 vs. $485 \mathrm{ppm}$ ) counterbalances the negative effects of climate change. Summer crops are generally more exposed than winter crops, as their growing cycle takes place when drought and heat stress increase in frequency and intensity. While an advanced sowing time may reduce these effects, a delayed sowing further reduces crop yield by shifting crop growing cycle towards the most unfavorable time of the season.

The effect of climate change with respect to the reference period was initially evaluated by considering the possible shifts in sowing dates or the use of different varieties, as outlined in Table 8 . In general, the results indicate that adaptation practices like advanced sowing constitute an effective measure to avoid the summer harsh conditions and reduce the expected impact of climate change. In particular, the early autumn sowing date is found to provide the highest yield for both wheat and barley over Cyprus with respect to the reference period. For RCP4.5, a general reduction of final yield was observed for wheat, ranging from $-1.2 \%$ in early autumn to $-4 \%$ in spring. Under RCP8.5, yield increases in early autumn by $+5.3 \%$ with a decreasing trend up to spring $(+3.2 \%)$. The same trend was observed for barley, where the yield slightly decreases in early/late autumn $(-2.2$ and $-1.4 \%)$ and slightly increased in winter and spring $(+0.6$ and $+0.5 \%)$ under RCP4.5. Conversely, under RCP8.5, the yield increases in a range from $+3.9 \%$ in early autumn to $7.5 \%$ in spring.

For the case of tomato, the late winter sowing times provided the highest yield for the reference period. The effect of climate change was generally positive when considering this time window for sowing, while it tended to decrease when shifting the sowing to late spring, where final yield was highly depressed with respect to the reference period up to $-27.4 \%$ under RCP4.5.

The highest yield for potato crop was reached when sowing was set in winter season (early/late) in the reference period. In future scenarios, the impact on yield was generally positive, especially for late autumn sowing under RCP8.5 that yielded an average increase of $23 \%$ with respect to the relevant sowing time.

Grapevine provided the highest yield with a late growing cycle in the reference period, which conversely was the most affected in both RCP4.5 and 8.5 future scenarios $(-18.0 \%$ and $-29.6 \%$, respectively).

A late growing cycle variety of olive tree exhibited the best performances over the island for the reference period. Similarly, both future scenarios had a general positive impact on final yield, especially for the early variety whose yield increased, with a few exceptions, up to $+5 \%$ in RCP8.5. For the late variety, yield increases were moderate. 
These data, in any case, represent the average performances of each crop simulated over the entire island, regardless of where the crops are actually cultivated. The same applies for management practices (sowing time) and varietal choice (late, medium and early) that, while in our simulations maximize final yield, may not be fully applicable in real conditions.

Table 8. Average crop yield response under different sowing seasons, precocity levels and future climate scenarios for Cyprus. RCP, representative concentration pathway.

\begin{tabular}{cccc}
\hline Crop & Sowing Season/Precocity Level & RCP4.5 & RCP8.5 \\
\hline \multirow{3}{*}{ Wheat } & Early autumn & $-1.2 \%$ & $5.3 \%$ \\
& Late autumn & $-1.4 \%$ & $4.3 \%$ \\
& Winter & $-2.3 \%$ & $3.1 \%$ \\
& Spring & $-4.0 \%$ & $3.2 \%$ \\
\hline \multirow{3}{*}{ Barley } & Early autumn & $-2.2 \%$ & $3.9 \%$ \\
& Late autumn & $-1.4 \%$ & $4.3 \%$ \\
& Winter & $0.6 \%$ & $5.5 \%$ \\
\multirow{3}{*}{ Tomato } & Spring & $0.5 \%$ & $7.5 \%$ \\
& Early winter & $5.3 \%$ & $9.2 \%$ \\
& Late winter & $-0.6 \%$ & $3.3 \%$ \\
& Early spring & $-6.2 \%$ & $-9.9 \%$ \\
\multirow{3}{*}{ Potato } & Late Spring & $-26.3 \%$ & $-27.4 \%$ \\
& Late autumn & $16.3 \%$ & $23.7 \%$ \\
\hline \multirow{2}{*}{ Grapevine } & Early winter & $18.5 \%$ & $22.3 \%$ \\
& Late winter & $15.3 \%$ & $20.1 \%$ \\
\hline \multirow{2}{*}{ Olive tree } & Early & $4.1 \%$ & $-1.9 \%$ \\
& Medium & $-7.9 \%$ & $-18.8 \%$ \\
\hline \multirow{2}{*}{} & Late & $-18.0 \%$ & $-29.6 \%$ \\
\hline
\end{tabular}

As such, for a real representation of the current growing conditions and management practices in Cyprus, we considered only simulations corresponding to the sowing times and varieties actually applied (Table 4) (business as usual, BAU). The same procedure was applied to assess the effect of climate change on crop yield change with respect to the reference period, under BAU conditions. The data on crop yield change were aggregated at municipal level by considering the weighted average of (i) the average expected yield change in each Cyprus municipality and (ii) the share of the cultivated area in each municipality to the total cultivated area of that crop in the Cyprus' municipalities. In a few words, if a crop is not cultivated in an area where a reduction in yield is expected, this reduction is not taken into account for the weighted average yield change.

As shown in Table 9, the results still point out that, under BAU conditions, on average, the crop mostly at risk is tomato, under both the RCP4.5 and RCP8.5 scenarios ( $-25 \%$ on average), while potato exhibited the best performances $(+12 \%)$. Winter crops such as winter and barley are less affected with respect to summer crops (tomato and grapevine), as their growing cycle partially avoids the effect of the summer period.

It should be noted that, in the case of tomato, crop simulations only consider open-field conditions, while tomato is mostly cultivated in greenhouses. As such, the outputs may be not fully representative of the expected impact of climate change.

Under extreme climatic scenarios, hot years are expected to mostly affect summer crops (tomato, olive tree, and grapevine), while winter and autumn crops are not affected (wheat and barley) or even are positively influenced (potato). Almost the same trend was observed for the dry years, but not for wheat and barley, which exhibited a high yield decrease $(-45 \%$ and $-51 \%)$ that was not observed for potato $(+20 \%)$, as the likely effect of a general shorter growing season that allowed potato crop to 
avoid the effect of dryness in summer. Grape and tomato were the most responsive in extremely wet years $(+5 \%$ and $+34 \%$, respectively), while the other crops showed a moderate negative effect (olive tree $-5 \%)$ or even large decrease $(-21 \%$ and $-33 \%$ for barley and wheat, respectively). The latter is somehow unexpected, as wet events were probably associated to cold events in winter that may have affected crop growth, as indicated by the results obtained for cold events. Under these extreme climatic years, both barley and wheat exhibited a reduction ( $-14 \%$ on average), while summer crops presented an increase in their performances, with the exception of tomato, as a result of a longer growing season induced by lower temperatures.

Table 9. Weighted average percentage yield change of the examined crops for the different climatic scenarios against the reference scenario.

\begin{tabular}{ccccccc}
\hline Crop & RCP4.5 & RCP8.5 & RCP8.5 Cold & RCP8.5 Dry & RCP8.5 Wet & RCP8.5 Hot \\
\hline Tomato & -23.89 & -26.25 & -10.28 & 1.05 & 4.52 & -50.46 \\
Potato & 8.12 & 13.83 & 24.77 & 20.13 & -12.16 & 29.66 \\
Olives & -6.00 & -6.12 & 7.65 & -21.04 & -4.87 & -22.13 \\
Grapes & -4.15 & -11.12 & 24.45 & -51.86 & 34.30 & -43.81 \\
Barley & -6.02 & -12.41 & -13.38 & -45.11 & -21.37 & -0.03 \\
Wheat & -1.94 & -5.28 & -13.53 & -51.50 & -32.80 & 1.22 \\
\hline
\end{tabular}

The results also point out that physiological adaptation to a dry climate may reduce the expected impact of climate change in summer season. For example, although olive tree develops during spring-summer, it suffers less in a warmer and dryer climate as it is well adapted to such conditions. In particular, Olive.CNR includes such an adaptation by increasing WUE in response to water stress, resulting into a lower water transpiration while keeping the photosynthetic efficiency.

The results of the crop simulation models obtained for Cyprus are in line with to date literature, which evidenced an asymmetric impact of climatic change on summer and winter crops, especially over the Mediterranean basin. As an example, Moriondo et al. [25] highlighted that, over the basin, drought and heat stress simulated for the next future in the A2 and B2 scenarios will have no adverse impact or even positive effects for durum wheat. On the same line, Abd-Elmabod et al. [32] predicted that, under the A1B scenario, sunflower in southern Spain is expected to be more subject to the impact of a warmer and dryer climate with respect to wheat. The same trend was observed on the European scale, where Webber et al. [33] demonstrated that drought and heat stresses would result in yield losses for maize, while gains are predicted for winter wheat. Ventrella et al. [34] indicated that a typical summer crop like tomato is at risk in Southern Italy in a $+2{ }^{\circ} \mathrm{C}$ scenario, if no adaptation measures are taken. Other studies indicated that progressive increase of temperature and drought will affect typical Mediterranean crops, such as olive tree and grapevine, that are expected to progressively shift to north from their original range [35,36]. This puts these crops at risk, especially in the south of the Mediterranean.

\subsection{Vulnerability of the Agricultural Sector}

The results of the social vulnerability assessment are presented at district level, while those of the economic vulnerability assessment are crop-specific and refer to the whole country. For the calculation of the composite social vulnerability indicator, equal weights were assigned to each indicator, with the exception of the two indicators referring on the size of agricultural population, which were first aggregated into a composite indicator. The social vulnerability scores for each district of Cyprus are presented in Table 10.

It is shown that Limassol is considered the most socially vulnerable district with respect to agriculture, as it ranks from "medium to high" to "high" in all four indicators, while Larnaca is the least vulnerable with a "low" and "low to Medium" ranking (see Table 1 for the correspondence with the nominal values). In specific, Nicosia district has the largest size of agricultural population as well 
the largest size of total population, as it is the capital of Cyprus. Although Limassol is ranked second with respect to the size of its agricultural population, it has the highest share of agricultural population with respect to its total population. The fact that the districts of Limassol, Nicosia, and Paphos include many mountainous municipalities with mainly an agricultural population explains the high share of agricultural population in these districts, as well as the high share of elderly farmers, as the population living in mountainous municipalities is older. The agricultural population in Famagusta district is low, as is its total population. In addition, the share of agricultural population in Famagusta is low compared with the other districts, which may be attributed to the high growth of the tourist and other associated economic sectors in the area. However, the income of farmers in Famagusta district is highly dependent on agriculture, as is also the case for the district of Limassol, compared with the other two districts. This may be attributed to the fact that quite profitable crops are cultivated in those areas, such as tomatoes; strawberries; and other open field and covered vegetables, including potatoes.

Table 10. Social vulnerability scores for each district of Cyprus (normalized).

\begin{tabular}{|c|c|c|c|c|c|}
\hline \multirow[b]{2}{*}{ District } & \multicolumn{2}{|c|}{ Agricultural Population } & \multirow{2}{*}{$\begin{array}{c}\text { Dependence } \\
\text { on Agriculture }\end{array}$} & \multirow{2}{*}{$\begin{array}{c}\text { Share of } \\
\text { Elderly } \\
\text { Farmers }\end{array}$} & \multirow{2}{*}{$\begin{array}{l}\text { Composite Social } \\
\text { Vulnerability }\end{array}$} \\
\hline & $\begin{array}{c}\text { Size of Agricultural } \\
\text { Population }\end{array}$ & $\begin{array}{c}\text { Share of Agricultural } \\
\text { Population }\end{array}$ & & & \\
\hline Nicosia & 5.0 & 4.0 & 3.7 & 3.9 & 4.0 \\
\hline Famagusta & 1.0 & 1.0 & 4.4 & 1.0 & 2.1 \\
\hline Larnaca & 2.4 & 2.2 & 1.0 & 1.1 & 1.5 \\
\hline Limassol & 4.0 & 5.0 & 5.0 & 5.0 & 4.8 \\
\hline Paphos & 2.4 & 3.6 & 1.2 & 2.7 & 2.3 \\
\hline
\end{tabular}

For the calculation of the composite economic vulnerability indicator, different weights were applied to the two sub-indicators, that is, 0.3 for price and 0.7 for annual revenues, which were considered to best reflect their relevant importance, based on the opinion of the involved stakeholders in Cyprus. After the application of weights, the scores were normalized again in the scale 1-5. The economic vulnerability scores for each crop are presented in Table 11. The table shows that, in terms of economic vulnerability, potatoes are ranked first, followed by olives.

Table 11. Economic vulnerability scores for each crop (normalized).

\begin{tabular}{cccc}
\hline Crop & Price & Annual Revenues & Composite Economic Vulnerability \\
\hline Tomatoes & 2.8 & 1.7 & 2.4 \\
Potatoes & 1.6 & 5.0 & 5.0 \\
Olives & 5.0 & 2.4 & 3.9 \\
Grapes & 1.7 & 1.5 & 1.6 \\
Barley & 1.0 & 1.5 & 1.4 \\
Wheat & 1.1 & 1.0 & 1.0 \\
\hline
\end{tabular}

\subsection{Total Impact}

The total impact results were calculated based on equations [1-3] and are presented for each crop and climatic scenario both cumulatively at national level (Table 12) and geospatially at municipal level for the whole country (Figure 1).

In particular, the values in Table 12 refer to the average of total impact values of the municipalities where each crop is cultivated. On the basis of RCP4.5, the highest impact scores are observed for tomatoes, followed by olives and grapes. In the case of RCP8.5, the hierarchy is somewhat different, with the highest impact scores observed for tomatoes, followed by grapes and then olives. In both scenarios, barley is in the fourth place, followed by wheat with low impact scores, while potatoes present negligible impact scores. In any case, the results of the table must be interpreted with caution, as a high impact score may only have a limited local effect, if the crop is cultivated to a small area (e.g., as in the case of tomato). 
Table 12. Total climate change impact scores for the examined crops (cumulative normalized results).

\begin{tabular}{ccc}
\hline \multirow{2}{*}{ Climatic Scenario/Crop } & \multicolumn{2}{c}{ Total Impact Scores } \\
\cline { 2 - 3 } & RCP 4.5 & RCP 8.5 \\
\hline Barley & 1.2 & 1.4 \\
Wheat & 0.5 & 0.7 \\
Tomatoes & 2.3 & 2.0 \\
Potatoes & 0.1 & 0.2 \\
Olives & 1.8 & 1.3 \\
Grapes & 1.3 & 1.7 \\
\hline
\end{tabular}

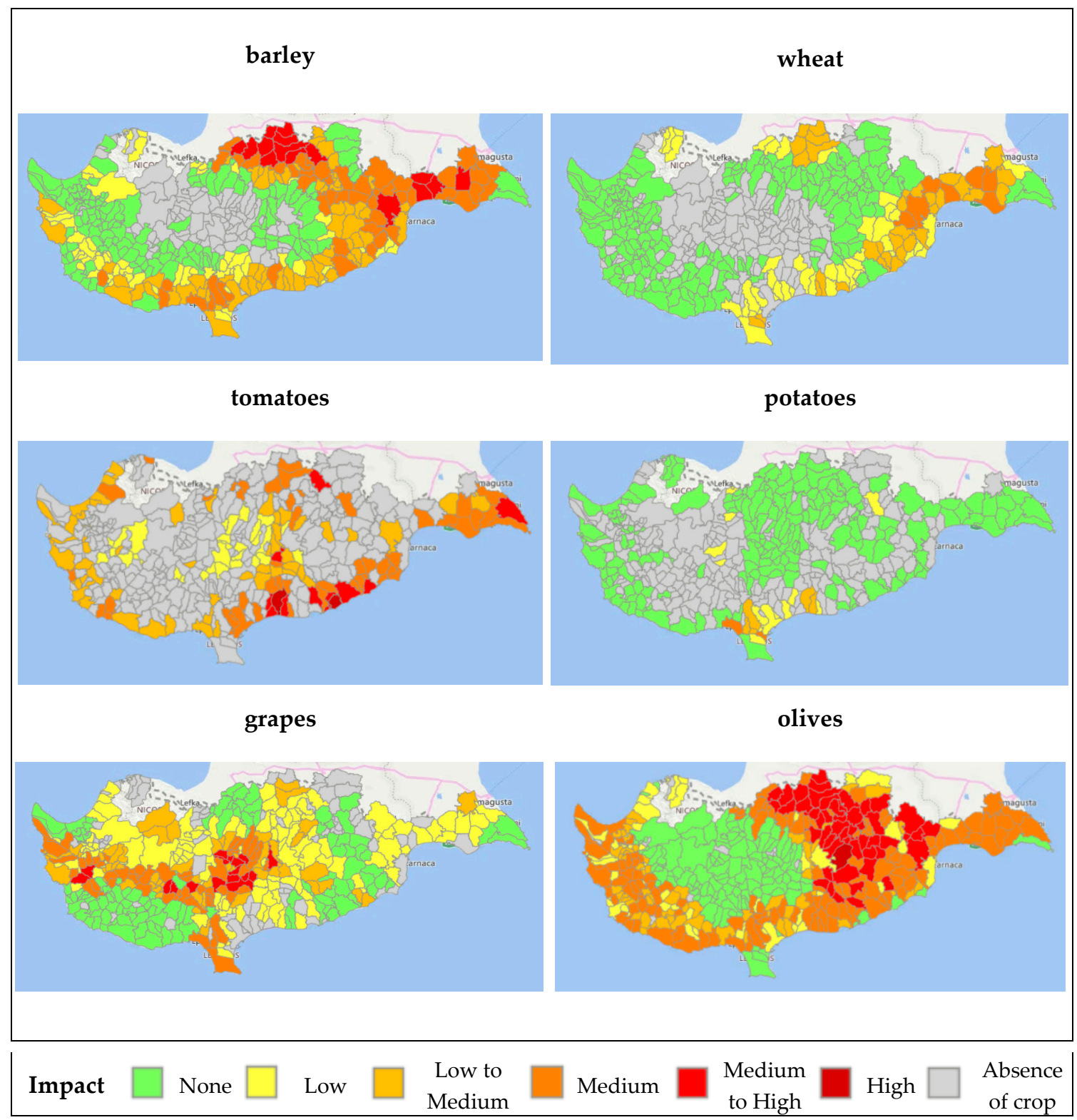

Figure 1. Estimated total climate change impacts on the agricultural sector of Cyprus (RCP4.5).

The impact assessment results are also presented through maps. However, owing to limited availability of space, it was decided to present only the results based on RCP4.5 (Figure 1). This selection is also based on the fact that RCP4.5 is a moderately optimistic scenario with respect to the implementation of greenhouse gas (GHG) mitigation policies, which is more in line with the Paris Agreement for limiting global temperature increase to $1.5^{\circ} \mathrm{C}$ by 2050 and the respective targets of 
the European Green Deal (COM (2019) 640) for achieving climate neutrality by 2050. Therefore, it is considered a more realistic scenario in contrast with RCP8.5, which does not take into account any intensification of mitigation policies.

As it may be seen in Figure 1, the cultivation of barley in Cyprus is expected to face from "low" up to "medium to high" total impacts in the future, while there are also areas where no adverse impacts are expected. The cultivation of wheat is not expected to face particular adverse impacts, with the latter not exceeding "medium" intensity. All areas cultivated with tomatoes are expected to face adverse total impacts, which in some cases reach "high" intensity. The cultivation of potatoes is not expected to be negatively affected by climate change, as there are very few municipalities where adverse impacts are foreseen. In the case of vineyard cultivation, the expected total impacts range from "low" to "medium to high". Lastly, the cultivation of olives is expected to be considerably affected with adverse impacts mostly ranging from "medium" to "medium to high", while the mountain area of Troodos is not expected to experience adverse impacts.

The results of the impact assessment may provide an indication of the intensity of impacts expected and of the areas that will be mostly affected; however, more detailed field research and consultation with stakeholders are necessary in order to determine what is needed for adaptation programming and how to develop local resilience.

\subsection{Economic Assessment}

In this section, the results of the assessment of climate change impacts on the expected changes in revenues from the examined crops under the different climatic scenarios are presented (Table 13). The results are calculated based on the expected change in yield (Table 9) and the average price of crops for the period 2010-2015 (Table 7), based on the assumption that the prices will remain stable in the future.

Table 13. Change in the expected total revenues from the examined crops and climatic scenarios compared to the average revenues of the period 2010-2015.

\begin{tabular}{ccc}
\hline \multirow{2}{*}{ Climatic Scenarios } & \multicolumn{2}{c}{ Change in Revenues } \\
\cline { 2 - 3 } & $\mathbf{( ` 0 0 0 ~} \mathbf{)}$ & $\mathbf{( \% )}$ \\
\hline RCP4.5 & -1535 & -1.8 \\
RCP8.5 & -1029 & -1.2 \\
RCP8.5 cold & 9377 & 11.0 \\
RCP8.5 dry & -6701 & -7.9 \\
RCP8.5 wet & -5285 & -6.2 \\
RCP8.5 hot & -1801 & -2.1 \\
\hline
\end{tabular}

The results in Table 13 show that the maximum losses in revenues are expected for an extreme dry year under RCP8.5 with an estimated reduction of $8 \%$, while in the case of an extreme cold year under RCP 8.5 , an increase of $11 \%$ in total revenues is expected. As may be seen, the changes in total revenues are not significant, because, under all scenarios, a loss in one crop is compensated by a gain in another crop. Although the overall agricultural economy of the country is not expected to be affected much, the farmers as well as the government should take action to increase the resilience of the agricultural sector, with a special focus on those crops and areas that are expected to be adversely affected by climate change impacts.

Following, the expected changes in total revenues for each crop based on the two main climatic scenarios are presented (Table 14). The results show that all crops except potatoes present a decrease in revenues in both climatic scenarios. However, the increase in potatoes compensates to a great extent the losses in the other crops and, therefore, the estimated overall reduction in total revenues is relatively small. In the case of RCP4.5, the great losses expected for tomatoes are compensated by the gains in 
revenues from the increased production of potatoes. In the case of RCP8.5, production of potatoes is even higher, thus compensating for additional losses in the other crops as well.

Table 14. Change in the expected total revenues per crop for the two main climatic scenarios.

\begin{tabular}{ccccc}
\hline \multirow{2}{*}{ Crops } & \multicolumn{2}{c}{ Change in Revenues-RCP4.5 } & \multicolumn{2}{c}{ Change in Revenues-RCP8.5 } \\
\cline { 2 - 5 } & $\mathbf{( ` 0 0 0 ~} \mathbf{\epsilon})$ & $\mathbf{( \% )}$ & $\mathbf{( ` 0 0 0 ~} \mathbf{)}$ & $\mathbf{( \% )}$ \\
\hline Tomatoes & -2560 & $-24 \%$ & -2813 & $-26 \%$ \\
Potatoes & 2954 & $8 \%$ & 5031 & $14 \%$ \\
Olives & -965 & $-6 \%$ & -984 & $-6 \%$ \\
Grapes & -348 & $-4 \%$ & -933 & $-11 \%$ \\
Barley & -522 & $-6 \%$ & -1075 & $-12 \%$ \\
Wheat & -94 & $-2 \%$ & -255 & $-5 \%$ \\
Total & -1535 & $-1.8 \%$ & -1029 & $-1.2 \%$ \\
\hline
\end{tabular}

The results of the economic assessment are in line with the results of the impact assessment, as data on crop yield and revenues have been taken into account in both cases. Slight differences between the results of the assessments may be attributed to the differentiation of the specific social characteristics of the areas where the crops are cultivated, such as in the case of grapes and barley. For example, on the basis of RCP4.5, grapes are ranked third in the impact assessment and fourth in economic losses, while the opposite is true for barley. This may be attributed to the fact that grapes are cultivated in mountain areas where the age of the population and the dependence on agriculture is high, and thus it was assigned with a highest social vulnerability score.

\section{Conclusions}

In this paper, the results of a detailed CCIV conducted for the agricultural sector of Cyprus is presented. The assessment is made with the employment of specialized climatic and crop models, while it incorporates quantified socio-economic vulnerability indicators, specific to the particular characteristics of the Cypriot agriculture. The results are aggregated at municipal level in order to support well-informed and robust adaptation planning at regional and local level.

The assessment was performed for the mean climatic conditions expected for the 2031-2060 period, based on RCP4.5 and RCP8.5, as well as for extreme climatic scenarios. Following, an economic assessment was made on the expected gains and losses, based on the foreseen crop yield change.

The results of climatic simulations indicated that, in Cyprus, future increases in temperature will be characterized by a strong seasonal trend, with the highest increases occurring in summer season especially under RCP8.5 scenario $\left(+3.8^{\circ} \mathrm{C}\right)$. On the other side, both annual total and seasonal precipitation are expected to decrease throughout the island, where the highest decreases up to $50 \%$ are expected during the summer period still under the RCP8.5 scenario.

The adopted crop growth modelling framework indicated that this climatic trend will affect mainly tomato, grapevine, and olive tree, whose growing cycle takes place during this summer season. By contrast, crops covering autumn-winter season, such as potato, barley, and wheat, are expected to partially avoid the harsh conditions occurring in summer, reducing the potential negative impact of climate change (wheat and barley) or even increasing their performances with respect to the present (potato).

On the basis of RCP4.5, the highest impact scores are observed for tomatoes followed by olives and grapes. In the case of RCP8.5, the hierarchy is somewhat different, with the highest impact scores observed for tomatoes, followed by grapes and then olives. In both scenarios, barley is in the fourth place, followed by wheat with low impact scores, while potatoes present negligible impact scores.

The results of the economic assessment show that the changes in total revenues are insignificant, because, under all scenarios, a loss in one crop is compensated for by a gain in another crop. However, the farmers as well as the government should take action to increase the resilience of the agricultural 
sector, with a special focus on those crops and areas that are expected to be adversely affected by climate change impacts.

Author Contributions: Conceptualization, C.P. and M.M. (Marco Moriondo); data curation, A.K. (Angeliki Konsta) and A.S.; formal analysis, C.P., M.M. (Marco Moriondo), I.L., A.K. (Anna Karali), C.D., L.B. and K.V.V.; funding acquisition, C.G.; investigation, C.P., M.M. (Marco Moriondo), I.L., A.K. (Anna Karali), L.B. and K.V.V.; methodology, C.P. and M.M. (Marco Moriondo); project administration, C.G.; supervision, M.M. (Marco Moriondo), M.L., M.M. (Marinos Markou) and C.G.; validation, C.P., M.M. (Marinos Markou), I.L., A.K. (Anna Karali), C.D., L.B., A.S. and M.M. (Marco Moriondo); visualization, A.K. (Angeliki Konsta); writing-original draft, C.P., M.M. (Marco Moriondo), I.L., A.K. (Anna Karali), C.D., L.B. and K.V.V.; writing-review \& editing, C.P., M.M. (Marco Moriondo), I.L., A.K. (Anna Karali), C.D. and L.B. All authors have read and agreed to the published version of the manuscript.

Funding: This research was funded by the LIFE programme for the Environment and Climate Action (2014-2020) in the framework of the project LIFE ADAPT2CLIMA "Adaptation to Climate Change Impacts on the Mediterranean Islands' Agriculture" (LIFE14 CCA/GR/000928).

Conflicts of Interest: The authors declare no conflict of interest. The funders had no role in the design of the study; in the collection, analyses, or interpretation of data; in the writing of the manuscript; or in the decision to publish the results.

\section{References}

1. European Environment Agency. Climate Change Adaptation in the Agriculture Sector in Europe; EEA Report No 04/2019; European Environment Agency: Copenhagen, Denmark, 2019.

2. European Environment Agency. National Climate Change Vulnerability and Risk Assessments in Europe, 2018; EEA Report No 01/2018; European Environment Agency: Copenhagen, Denmark, 2018.

3. Downing, C. Assessing Adaptation Knowledge in Europe: Vulnerability to Climate Change Final Report; Project Number: DESNL16057 (CLIMA.C.3/SER/340202/2015/719923); Ecofys. DG CLIMA, European Commission. 2017. Available online: https://ec.europa.eu/clima/sites/clima/files/adaptation/what/docs/ climate_change_vulnerability_en.pdf (accessed on 30 March 2020).

4. Republic of Cyprus. National Adaptation Strategy to Climate Change; Department of Environment, Ministry of Agriculture, Rural Development and Environment: Nicosia, Cyprus, 2017.

5. CYPADAPT. Report on the Future Climate Change Impact, Vulnerability and Adaptation Assessment for the Case of Cyprus-DELIVERABLE 3.4. Project CYPADAPT (LIFE10 ENV/CY/000723). 2012. Available online: http://cypadapt.uest.gr/wp-content/uploads/DELIVERABLE3.4.pdf (accessed on 20 February 2020).

6. Zittis, G.; Bruggeman, A.; Camera, C.; Hadjinicolaou, P.; Lelieveld, J. The added value of convection permitting simulations of extreme precipitation events over the eastern Mediterranean. Atmos. Res. 2017, 191, 20-33. [CrossRef]

7. Life ADAPT2CLIMA. Knowledge Capitalization Concerning the Sectors of Agriculture in the Regions of Crete, Sicily and Cyprus, Deliverable C1.1. Project ADAPT2CLIMA (LIFE14 CCA/GR/000928). 2016. Available online: http://adapt2clima.eu/uploads/2017/Del_C1_1.pdf (accessed on 30 March 2020).

8. Ministry of Agriculture, Natural Resources and Environment. Cyprus Rural Development Programme 2014-2020, Version 1.4. Republic of Cyprus. 2015. Available online: http:/www.paa.gov.cy/moa/paa/paa.nsf/ All/3763CA3C237DF5F3C22580F7003E192B (accessed on 1 May 2020).

9. CYSTAT. Agricultural Statistics 2015, Series II, Reports No. 45; Cyprus Statistical Service: Nicosia, Cyprus, 2017.

10. Stöckle, C.O.; Donatelli, M.; Nelson, R. CropSyst, a cropping systems simulation model. Eur. J. Agron. 2003, 18, 289-307. [CrossRef]

11. Moriondo, M.; Leolini, L.; Brilli, L.; Dibari, C.; Tognetti, R.; Giovannelli, A.; Rapi, B.; Battista, P.; Caruso, G.; Gucci, R.; et al. A simple model simulating development and growth of an olive grove. Eur. J. Agron. 2019, 105, 129-145. [CrossRef]

12. Leolini, L.; Bregaglio, S.; Moriondo, M.; Ramos, M.C.; Bindi, M.; Ginaldi, F. A model library to simulate grapevine growth and development: Software implementation, sensitivity analysis and field level application. Eur. J. Agron. 2018, 99, 92-105. [CrossRef] 
13. IPCC. Summary for policymakers. In Climate Change 2014: Impacts, Adaptation, and Vulnerability. Part A: Global and Sectoral Aspects. Contribution of Working Group II to the Fifth Assessment Report of the Intergovernmental Panel on Climate Change; Field, C.B., Barros, V.R., Dokken, D.J., Mach, K.J., Mastrandrea, M.D., Bilir, T.E., Chatterjee, M., Ebi, K.L., Estrada, Y.O., Genova, R.C., et al., Eds.; Cambridge University Press: Cambridge, UK; New York, NY, USA, 2014; pp. 1-32.

14. GIZ \& EURAC. Risk Supplement to the Vulnerability Sourcebook; Guidance on how to apply the Vulnerability Sourcebook's approach with the new IPCC AR5 concept of climate risk; GIZ \& EURAC: Bonn, Germany, 2017.

15. Schauser, I.; Otto, S.; Schneiderbauer, S.; Harvey, A.; Hodgson, N.; Robrecht, H.; Morchain, D.; Schrander, J.J.; Khovanskaia, M.; Celikyilmaz-Aydemir, G.; et al. Urban Regions: Vulnerabilities, Vulnerability Assessments by Indicators and Adaptation Options for Climate Change Indicators; ETC/ACC: Bilthoven, The Netherlands, 2010.

16. OECD. Handbook on Constructing Composite Indicators: Methodology and User Guide. Technical Report. Organisation for Economic Co-Operation and Development; OECD Publishing: Paris, France, 2008.

17. Life ADAPT2CLIMA. Stakeholder Engagement Strategy and Communication Plan-Deliverable A1.1. Project ADAPT2CLIMA (LIFE14 CCA/GR/000928); Greece. 2015. Available online: http://adapt2clima.eu/ uploads/2020/ADAPT2CLIMA_DEL_A1_1.pdf (accessed on 30 May 2020).

18. Strandberg, G.; Bärring, A.; Hansson, U.; Jansson, C.; Jones, C.; Kjellström, E. CORDEX scenarios for Europe from the Rossby Centre regional climate model RCA4. Rep. Meteorol. Climatol. 2014, 116, 84.

19. Collins, W.J.; Bellouin, N.; Doutriaux-Boucher, M.; Gedney, N.; Halloran, P.; Hinton, T.; Woodward, S. Development and evaluation of an Earth-System model-HadGEM2. Geosci. Model Dev. 2011, 4, 1051-1075. [CrossRef]

20. Martin, G.M.; Milton, S.F.; Senior, C.A.; Brooks, M.E.; Ineson, S.; Reichler, T.; Kim, J. Analysis and Reduction of Systematic Errors through a Seamless Approach to Modeling Weather and Climate. J. Clim. 2010, 23, 5933-5957. [CrossRef]

21. Life ADAPT2CLIMA. Future Projections on Climatic Indices with Particular Relevance to Agriculture for the Three Islands (Coarse Resolution) and for Each Agricultural Pilot Area (Fine Resolution)—Deliverable C3. Project ADAPT2CLIMA (LIFE14 CCA/GR/000928); Greece. 2017. Available online: http://adapt2clima.eu/ uploads/2017/ADAPT2CLIMA_DEL_C.3_Final_3.pdf (accessed on 20 February 2020).

22. Taylor, K.E. Summarizing multiple aspects of model performance in a single diagram. J. Geophys. Res. 2001, 106, 7183-7192. [CrossRef]

23. Thomson, A.M.; Calvin, K.V.; Smith, S.J.; Kyle, G.P.; Volke, A.; Patel, P.; Delgado-Arias, S.; Bond-Lamberty, B.; Wise, M.A.; Clarke, L.E.; et al. RCP4.5: A pathway for stabilization of radiative forcing by 2100. Clim. Chang. 2011, 109, 77. [CrossRef]

24. Riahi, K.; Rao, S.; Krey, V.; Cho, C.; Chirkov, V.; Fischer, G.; Kindermann, G.; Nakicenovic, N.; Rafaj, P. RCP 8.5-A scenario of comparatively high greenhouse gas emissions. Clim. Chang. 2011, 109, 33. [CrossRef]

25. Moriondo, M.; Giannakopoulos, C.; Bindi, M. Climate change impact assessment: The role of climate extremes in crop yield simulation. Clim. Chang. 2011, 104, 679-701. [CrossRef]

26. CYSTAT. Agricultural Census 2010, Agricultural Statistics, Series I, Report No. 8; Cyprus Statistical Service: Nicosia, Cyprus, 2010.

27. CYSTAT. Population Census. Population Recorded by Gender, Age, District, Municipality/Community (1.10.2011); Cyprus Statistical Service: Nicosia, Cyprus, 2011.

28. CYSTAT. Agricultural Statistics 2014, Series II, Reports No. 44; Cyprus Statistical Service: Nicosia, Cyprus, 2016.

29. CYSTAT. Agricultural Statistics 2013, Series II, Reports No. 43; Cyprus Statistical Service: Nicosia, Cyprus, 2015.

30. CYSTAT. Agricultural Statistics 2011-2012, Series II, Reports No. 42; Cyprus Statistical Service: Nicosia, Cyprus, 2015.

31. CYSTAT. Agricultural Statistics 2009-2010, Series II, Reports No. 41; Cyprus Statistical Service: Nicosia, Cyprus, 2012.

32. Abd-Elmabod, S.K.; Muñoz-Rojas, M.; Jordán, A.; Anaya-Romero, M.; Phillips, J.D.; Laurence, J.; Zhang, Z.; Pereira, P.; Fleskens, L.; van der Ploeg, M.; et al. Climate change impacts on agricultural suitability and yield reduction in a Mediterranean region. Geoderma 2020, 374, 114453. [CrossRef]

33. Webber, H.; Ewert, F.; Olesen, J.E.; Müller, C.; Fronzek, S.; Ruane, A.C.; Bourgault, M.; Martre, P.; Ababaei, B.; Bindi, M.; et al. Diverging importance of drought stress for maize and winter wheat in Europe. Nat. Commun. 2018, 9, 4249. [CrossRef] [PubMed] 
34. Ventrella, D.; Charfeddine, M.; Moriondo, M.; Rinaldi, M.; Bindi, M. Agronomic adaptation strategies under climate change for winter durum wheat and tomato in southern Italy: Irrigation and nitrogen fertilization. Reg. Environ. Chang. 2012, 12,407-419. [CrossRef]

35. Moriondo, M.; Jones, G.V.; Bois, B.; Dibari, C.; Ferrise, R.; Trombi, G.; Bindi, M. Projected shifts of wine regions in response to climate change. Clim. Chang. 2013, 119, 825-839. [CrossRef]

36. Moriondo, M.; Trombi, G.; Ferrise, R.; Brandani, G.; Dibari, C.; Ammann, C.M.; Lippi, M.M.; Bindi, M. Olive trees as bio-indicators of climate evolution in the Mediterranean Basin. Glob. Ecol. Biogeogr. 2013, 22, 818-833. [CrossRef]

(C) 2020 by the authors. Licensee MDPI, Basel, Switzerland. This article is an open access article distributed under the terms and conditions of the Creative Commons Attribution (CC BY) license (http://creativecommons.org/licenses/by/4.0/). 